\title{
The Role of Parental Involvement in Classroom Life in Greek Primary and Secondary Education
}

\author{
Yota Xanthacou, Thomas Babalis, Nektarios A. Stavrou \\ University of Athens, Athens, Greece \\ Email: xanthakou@rhodes.aegean.gr, nstavrou@phed.uoa.gr, tbabalis@primedu.uoa.gr
}

Received October $16^{\text {th }}, 2012$; revised November $14^{\text {th }}, 2012$; accepted December $15^{\text {th }}, 2012$

\begin{abstract}
Research findings indicated the importance of parental role in the educational process of children providing support for the strong connection between parental role and educational process. The purpose of the present study was to examine the role of parental involvement in classroom life in Greek Primary and Secondary education. A sample of one hundred and fifty five (155) students (69 boys, 86 girls) ranging in age from eleven to fifteen years volunteered to participate in this study. For the purpose of the study, students completed the Classroom Life Measure, which took place during their lessons. The results showed that the pressure from their parents to the study the lessons contributed to the increase of the state-anxiety felt by children, but simultaneously to increase of the negative self-esteem. The parents of primary school students are engaged in a higher degree with the homework, but also seek their children's participation in school activities.
\end{abstract}

Keywords: Parental Involvement; Classroom Life; Anxiety; Self-Esteem

\section{Introduction}

International bibliography and research point out the importance of parental role in the educational process of children, and the parental desire to contribute to the improvement of those conditions, which could help their children achieve higher levels of performance and success. A variety of research findings (Babalis \& Katsaouni, 2011) demonstrate the importance of the characteristics of effective schools concerning the development of a healthy climate of communication and collaboration between school and family and prove that parental involvementrelated to the learning procedure-not only contributes to the acquisition of knowledge, but also to social and sentimental progress. Simultaneously, various benefits arise for everyone involved, as well as teachers and parents (Berner, 2004; Christenson \& Sheridan, 2001; Epstein, 1995, 2001; Epstein, Coates et al., 1997; Epstein, Sanders et al., 2002; Hoover-Dempsey et al., 1997; Patrikakou, Weissber et al., 2005). However, some important factors were not investigated at the aforementioned studies, such as psychological traits of children, for example state-anxiety, which is taken into account in the present study in relation with parental involvement. Moreover, it is true that the school which welcomes parents is a school open to society and its changes. During the last decade, in many countries, the educational policy has involved pupils' parents in the educational organization, seeing them as important co-operators. For that, many special programs are applied trying to actively enrol parents in school events.

International organizations, universities, political entities responsible for education, research centres, scientific associations, social organizations etc. are seriously occupied with this subject. In 1996 UNESCO (Delor) pointed out the need of co-operation among family, school and society. The European Union took into account this dimension and tried to reduce school dropouts and the increase of the contribution to life-long learning. For more than 20 years at Harvard University functions the research program called "Harvard Family Research Project", which is addressed to teachers, parents, society members and to all responsible for the engraving of educational policy, providing information to reinforce and coordinate their action and facilitate the cooperation among school, family and society. In US universities specific research institutes have been established, such as the Institute of Responsive Education at Boston University and the Centre on Families, Communities, Schools and Children Learning at Johns Hopkins University. In 1991 the International Network of Scholars of Home-School Relations was founded with more than 200 members from 30 countries and in 1995 European Research Network about Parents in Education followed.

\section{The Role of Parental Involvement in the Relationship between the School and the Students' Family}

The role of parental involvement is better understood when the parents and teachers understand one another's expectations, simultaneously keeping communication which will allow both sides to acknowledge the progress and the child's behaviour at home and at school; the way students perform on homework, their interests, talents, school attitudes and social interactions as well (Albright \& Weissberg, 2010). All these compose the axes on which our study focuses, which are supplemented with the following factors: teacher and student academic and personal support, extrinsic motivation, self-esteem and state-trait anxiety. The combination of the concrete psychometric tools adds novelty to our research. The models which refer to the relationship between school and family, have dominated since 1980, showing the importance which is rendered to the interaction among people and groups involved in the educational procedure. The beginning happened with Bronfenbrenner's (1979) bio-ecosystemic model supporting that a person, during his life, par- 
ticipates in many different systems connected to one another with an interactive and interdependent relationship. Epstein's (1995) model of overlapping spheres of influence portray the three spheres, family, school and society, which through their influences pupils are evolved and learn as well.

Then, Ryan and Adam (1995) emphasize on the whole of the individual characteristics of a family's members and mutual function related to the child and his/her development and their proximity of influence on the child's behaviour and effects. Recently, Hoover-Dempsey's and Sandler's model (2005) of parental involvement targeted understanding the reasons why parents ought to be involved in their children's education. Christenson and Sheridan (2001) believe that an effective communication is the foundation of family's involvement in education. Parents involved in children's activities - both at home and at school - understand the benefit that derives:

1) Improvement of their relationships with their children.

2) Children's progress.

3) Better capacity to support children doing their homework.

4) Better estimation of teacher's effectiveness.

Parents received feedback through the satisfaction coming from the new relation with the school, especially when teachers encourage and reinforce their participation. A prerequisite for fertile communication among parents, teachers and school headmasters is that their relationship must be based on mutual trust (Haynes et al., 1996), which is the indispensable ingredient for the success of effective communication and development of a healthy relationship between school and family (Christenson \& Sheridan, 2001). Thereby, children feel satisfied in their life, an indicator of general positive self-esteem, as a result of the mutual understanding between the important "others" who are engaged in their daily routine. The "self-esteem" criterion, which has not been so far fairly examined relative to parental involvement, is highlighted in the present research including both the positive and the negative aspect of it.

School should be the first to take initiatives related to school's communication between family and society (Milonakou-Keke, 2006). In practice as she points out, the cooperation between school and family reinforces the collaborative atmosphere and drives parents, pupils and teachers to a better understanding of the targets of the school. Epstein (2001) declares that if parents are well-informed, if they know what exactly is happening at school, if they are encouraging and if, in general, they are involved in the life of their child, pupils have more positive attitudes toward education, higher ambitions and a better presentation. Here are some aspects of parental involvement:

- Parents are informed and give necessary information to school staff.

- They are involved in educational activity at home, supervising the child in order to complete his/her homework.

- Participate in school decisions and administration.

- Have frequent communication with the teacher and are informed not only about their child's performance, but also the educational dimension of their parental role.

- Localize the needs of children in order to be capable to helping them.

- Have great expectations related to the child's performance.

- Offer help to school, such as volunteering, etc.

Factors that usually influence parental involvement are related to the demographical characteristics of parents, such as sex, social and economic status, educational status, profession, nationality, etc. Its manifestation depends on the attitudes and expectations of parents that, according to research, are connected to the increased motives of their children for school success. Thus, school, with its rules, its demands and the characteristics of the headmaster's/teachers' personality can welcome or impede parental involvement.

According to a series of research findings (Christenson \& Sheridan, 2001; Epstein, 2001; Georgiou, 2001) the more usual types of parental involvement are: supervision of school behavior, control of out-of-school behavior, help with homework, communication with the school. Undoubtedly, control of out-ofschool behavior and frequent communication with school are the most effective activities.

In Greece the parents' participation in school happenings has been institutionalized with the obligatory establishment in every school unit of a parent guardian association consisting of all the parents of the students. Nevertheless, the law seems to mostly cover the formal and legal dimension of the parents' involvement in the school unit and shows less interest in an essential pedagogic relationship between the family and the school. As well as this, research related to the communication and cooperation between family and school is very limited. There is now the necessity for researching the role of parental involvement in the school to result in valuable conclusions concerning the real image of the Greek educational system.

The purpose of the present study was to examine the relationship between classroom life, students' self-esteem, anxiety and parental involvement in Primary and Secondary education students. More specifically, the present study aimed at examining the differences based on gender and education level in students' classroom life as well as the level at the type of parental involvement.

\section{Methodology}

\section{Participants}

A sample of one hundred and fifty five (155) students (69 boys, $44.5 \%$; 86 girls, $55.5 \%$ ) volunteered to participate in this study. They represented four grades of Primary and Secondary Education (41 students of 5th Grade Primary Education, 59 students of 6th Grade Primary Education, 26 students of 1st Grade Secondary Education and 21 students of 2nd Grade Secondary Education). The students ranged in age from eleven (11) to fifteen $(15)$ years $(M=12.42, S D=1.30)$.

\section{Instrumentation}

\section{Classroom Life Measure}

First, the students completed the Classroom Life Measure (Johnson D. W., \& Johnson R., 1983; Johnson, D. W., Johnson, R. T., Buckman, \& Richards, 1985). The original instrument of Classroom Life Measure is a 90 -item self-report scale measureing students' feeling in the educational environment and especially in their classroom. The 90 items constitute 17 factors, out of which six factors were examined in the present study. Specifically, the followings factors were measured in the present study: 1) teacher academic support (4 items) (Cronbach $a=.65$ ); 2) teacher personal support (4 items) (Cronbach $a=.67) ; 3$ ) student academic support (4 items) (Cronbach $a=.69)$; 4) student personal support (5 items) (Cronbach $a=.77) ; 5$ ) extrinsic motivation-social support (5 items) (Cronbach $a=.67$ ) and 6) academic self-esteem ( 5 items) (Cronbach $a=.68$ ). The value of each factor is the sum of the items of the factor divided by 
the number of items of each factor. The answers were given in 5 -point type scale ranging from 1 to 5 , where high values indicate high levels of each dimension.

\section{State-Trait Anxiety Inventory}

The State-Trait Anxiety Inventory for Children (STAI-C; Spielberger, Gorsuch, Lushene, 1970) which was constructed by Spielberger, Edwards, Lushene, Montuori and Platzek (1973) and was adopted to the Greek population by Psychountaki (1995) and Psychountaki, Zervas, Karteroliotis and Spielberger (2003), has been developed in order to measure the state-trait anxiety of children in susceptibility conditions (Cronbach $a$ $=.87$ ).

\section{Self-Esteem Scale}

The Self-Esteem Scale (Rosenberg, 1965) has been developed in order to evaluate the personal estimation of the student. The instrument is being administered with the instruction to complete it according to "how one usually feels in his/her life". The instrument consists of ten (10) questions, which are summarized in a single factor that refers to general self-esteem (Cronbach $a=.81$ ). Also, it is possible to result in two value factors, which are positive self-esteem (Cronbach $a=.90$ ) and negative self-esteem (Cronbach $a=.91$ ).

\section{Parental Involvement Scale}

The Parental Involvement Scale (Georgiou, 2000) has been developed in order to examine the degree of participation, interest and involvement of parents in the educational process and the overall education of their children. The Parental Involvement Scale consists of five (5) factors, which evaluate five different dimensions-factors of parental involvement, namely: 1) homework (Cronbach $a=.84$ ); 2) pressure (Cronbach $a=.70$ ); 3) participation in school activities (Cronbach $a=.67)$; 4) child's personality development (Cronbach $a=.65$ ) and 5) control (Cronbach $a=.68$ ). The value of each factor-dimension is the sum of the items of the factor divided by the number of items of each factor and is ranging from 0 to 4 , where high values indicate high levels of each dimension.

\section{Procedure of the Instrumentation Completion-Data Collection}

The instrumentation completion was done during the lessons of the students in the context of two administrations. Specifically, for the purposes of the study, students completed the Classroom Life Measure, which took place during the lessons of the students in the classroom they were studying. The administration and completion of the scale was done in the presence of the researcher, who gave all the necessary clarifications, thus contributing to a better understanding of the items. The duration of Life Scale Measuring Classroom completion was about forty (40) minutes. In the second administration students completed the State-Trait Anxiety Inventory and the Self-Esteem Scale. The duration of the questionnaires completion was about twenty (20) minutes and was done again in the presence of the researcher to resolve any queries on the part of students and provide all the necessary explanations and instructions.

Regarding the instrumentations which were completed by the parents of the students, the Parental Involvement Scale was sent to parents of students through a sealed envelope. Surveyed parents were distributed, through their children, a file contain- ing: 1) a letter explaining to parents the purpose and importance of research, as well as the necessary explanations concerning the confidentiality and anonymity of responses; 2) the measureing instrument and 3) a responsive file. At the same time, parents were informed that they should return the completed questionnaires within ten (10) days.

\section{Statistical Analysis of the Research Data}

The method of multiple analysis of variance; MANOVA was used to investigate the purposes of the study. Specifically, differences in factors of Parental Involvement Scale between the two genders (boys, girls), students of primary and secondary Education were examined, as well as between students with low and high overall and school self-esteem. The Pearson r coefficient was used to examine the relationships between the examined variables (Cohen, 1988). The statistical package that we used in the present study is SPSS Ver. 19.0.

\section{Results}

\section{Correlations between the Examined Variables in the Total Number of the Students in the Sample}

Tables 1-3 present the correlations between the examined variables of the research. Specifically, the correlations between the factors of the following instrumentation were examined: 1) Classroom Life Scale; 2) State-Trait Anxiety Inventory; 3) Self-Esteem Scale and 4) Parental Involvement Scale.

Correlational analysis. Significant intercorrelations were found among the Parental Involvement Scale subscales (Table 1). The factors of Parental Involvement Scale indicated low to medium value intercorrelations, ranging from .09 to .47 . In particular, the highest correlations occurred between the control factor and the factors homework, pressure and personality development of the child. Also, moderate positive correlations were found between the factor homework with the factors pressure and participation in school activities, and between the factors participation in school activities and personality development, indicating that parents' characteristics and behavior interact in order to form their behavior.

Table 2 presents the results of the intercorrelations between the factors of Parental Involvement Scale and Classroom Life Measure Subscales. The results showed the existence of significant correlations between the factors of both instrumentations. Specifically, academic self-esteem was positively correlated with school activities $(\mathrm{r}=.32, p<.001)$ and negatively to pressure $(\mathrm{r}=-.21, p<.01)$, while the factor extrinsic motivation-social support showed a positive correlation with the factor pressure $(\mathrm{r}=.20, p<.01)$. The aforementioned results indicate that there is a correlation between the pressure that parents exert to their child and the way the students experience the classroom life.

Table 3 presents the results of the correlations between the factors of Parental Involvement Scale, State-Trait Anxiety Inventory and Self-Esteem Scale in the whole sample. Positive correlations were found between extrinsic motivation-social support factors and pressure, as well as between the factors participation in school activities and school self-esteem. On the other hand, a negative correlation was found between pressure and school self-esteem. The results indicate that the level of pressure that parents exert to their children is related to an in- 
Table 1.

Intercorrelations among parental involvement scale subscales.

\begin{tabular}{cccccc}
\hline & Homework & Pressure & School activities & Personality development & Control \\
\hline Homework & 1.00 & $.30^{* * *}$ & $.34^{* * *}$ & $.25^{* *}$ & $.47^{* * *}$ \\
Pressure & & 1.00 & .09 & $.19^{*}$ & $.47^{* * *}$ \\
School activities & & & 1.00 & $.32^{* * *}$ & $.20^{* *}$ \\
Personality development & & & & 1.00 & $.42^{* * *}$ \\
Control & & & & & 1.00 \\
\hline
\end{tabular}

Note: ${ }^{*} p<.05 ;{ }^{* *} p<.01 ;{ }^{* * *} p<.001$.

Table 2.

Intercorrelations among parental involvement scale and classroom life measure subscales.

\begin{tabular}{ccccc}
\hline & Teacher support & Students support & Extrinsic motivation-social support & Academic self-esteem \\
\hline Homework & .03 & .00 & .10 & .14 \\
Pressure & -.13 & -.12 & $.20^{* *}$ & $-.21^{* * *}$ \\
School activities & .00 & .03 & .00 & $.32^{* * *}$ \\
Personality development & -.01 & .00 & $-.19^{*}$ & .12 \\
Control & -.07 & .00 & .14 & -.11 \\
\hline
\end{tabular}

Note: ${ }^{*} p<.05 ;{ }^{* *} p<.01 ;{ }^{* * *} p<.001$.

Table 3.

Correlations among factors of parental involvement scale, state-trait anxiety inventory and self-esteem scale in the whole sample.

\begin{tabular}{ccccc}
\hline & State-trait anxiety & Positive self-esteem & Negative self-esteem & General self-esteem \\
\hline Homework & -.10 & .02 & -.05 & .07 \\
Pressure & $.36^{* * *}$ & -.15 & $.23^{* *}$ & $-.36^{* * *}$ \\
School activities & -.07 & -.14 & -.14 & -.01 \\
Personality development & -.01 & -.04 & -.03 & -.01 \\
Control & .13 & -.03 & .15 & $-.16^{*}$ \\
\hline
\end{tabular}

Note: ${ }^{*} p<.05 ;{ }^{* *} p<.01 ;{ }^{* * *} p<.001$.

crease in child's anxiety and negative self-esteem, whereas in the other hand elevated pressure by the parents decrease child's general self-esteem.

\section{Differences in Factors of Parental Involvement Scale}

The Tables 4-7 present the differences in factors of Parental Involvement Scale (homework, pressure, participation in school activities, personality development, control). Specifically, differences according to the gender (boys, girls), the education level (Primary education, Secondary education), students' general self-esteem (low, high) and students' academic self-esteem (low, high) were examined.

Table 4 presents the differences between the students of Primary and Secondary education in the Parental Involvement Scale factors. The results of multiple analysis of variance did not support the existence of statistically significant differences between boys and girls (Wilks' $\Lambda=.958, F(1,153)=1.295, n s$, $\eta_{p}^{2}=.042$ ), indicating that there is no difference between boys and girls in the involvement of their parents; involvement.

Table 5 presents the differences between the students of primary school and high school in the factors of Parental Involvement Scale. The results of multiple analysis of variance showed the existence of statistically significant differences between students of primary school and high school (Wilks' $\Lambda$ $\left.=.919, F(1,153)=2.611, p<.05, \eta_{p}^{2}=.081\right)$. The follow-up analy- ses showed the existence of statistically significant differences in the factors: 1$)$ homework $(F(1,153)=7.752, p<.01$,
Table 4.

Mean $(M)$, standard deviations $(S D)$ of boys and girls in the factors of the parental involvement scale.

\begin{tabular}{ccc}
\hline & Boys & Girls \\
\cline { 2 - 3 } & $M(S D)$ & $M(S D)$ \\
\hline Homework & $2.17(1.02)$ & $2.15(1.12)$ \\
Pressure & $2.68(1.01)$ & $2.60(.91)$ \\
School activities & $2.66(.82)$ & $2.73(.092)$ \\
Personality development & $2.51(.88)$ & $2.80(.70)$ \\
Control & $2.29(1.08)$ & $2.36(1.05)$ \\
\hline
\end{tabular}

Table 5.

Mean $(M)$, standard deviations $(S D)$ in parental involvement scale subscales between primary and secondary education students.

\begin{tabular}{ccc}
\hline & $\begin{array}{c}\text { Primary education } \\
\text { students }\end{array}$ & $\begin{array}{c}\text { Secondary education } \\
\text { students }\end{array}$ \\
\cline { 2 - 3 } & $M(S D)$ & $M(S D)$ \\
\hline Homework & $2.33(1.01)$ & $1.84(1.11)$ \\
Pressure & $2.57(.99)$ & $2.71(.91)$ \\
School activities & $2.81(.86)$ & $2.50(.87)$ \\
Personality development & $2.72(.76)$ & $2.57(.86)$ \\
Control & $2.37(1.00)$ & $2.26(1.16)$ \\
\hline
\end{tabular}


$\left.\eta_{p}^{2}=.048\right)\left(M_{\text {difference }}=.49\right)$ and 2$)$ participation in school activities $\left(F(1,153)=4.638, p<.05, \eta_{p}^{2}=.029\right)\left(M_{\text {difference }}\right.$ $=.31$ ). The results revealed that parents behavior differentiates based on whether their children are in Primary or Secondary education.

Table 6 presents the differences between students with low and high self-esteem in the factors of Parental Involvement Scale. Multiple analysis of variance results showed the existence of statistically significant differences between students of low and high general self-esteem (Wilks' $\Lambda=.856, F(1,153)=$ 4.816, $\left.p<.001, \eta_{p}^{2}=.144\right)$. The follow-up analyses showed the existence of statistically significant differences in the factors: 1) pressure $\left(F(1,153)=15.790, p<.001, \eta_{p}^{2}=.097\right)$ $\left(M_{\text {difference }}=.60\right)$ and 2$)$ control $\left(F(1,153)=5.920, p<.05, \eta_{p}^{2}\right.$ $=.039)\left(M_{\text {difference }}=.42\right)$. The results showed that the higher the level of pressure and control by the parents in their children behavior the lower the level of boys' and girls' self-esteem.

Table 7 presents the differences between students with low and high academic self-esteem in the factors of Parental Involvement Scale. The results of the multiple analysis of variance showed the existence of statistically significant differences between students of low and high academic self-esteem (Wilks' $\left.\Lambda=.856, F(1,153)=4.945, p<.001, \eta_{p}^{2}=.144\right)$. The follow-up analyses showed the existence of statistically significant differences in the factors: 1$)$ pressure $(F(1,153)=5.139, p<.05$, $\left.\eta_{p}^{2}=.025\right)\left(M_{\text {difference }}=.35\right)$ and 2$)$ control $(F(1,153)=5.920$, $\left.p<.05, \eta_{p}^{2}=.039\right)\left(M_{\text {difference }}=.19\right)$. As in the previous result, the low level of students academic self-esteem is related to a higher level of pressure and control by the parents in their children behavior.

\section{Discussion and Conclusion}

The results of the intercorrelations between the factors of

Table 6.

Mean $(M)$, standard deviations $(S D)$ in Parental Involvement Scale subscales between students of low and high general self-esteem.

\begin{tabular}{ccc}
\hline & $\begin{array}{c}\text { Low general } \\
\text { self-esteem }\end{array}$ & $\begin{array}{c}\text { High general } \\
\text { self-esteem }\end{array}$ \\
\cline { 2 - 3 } & $M(S D)$ & $M(S D)$ \\
\hline Homework & $2.16(1.07)$ & $2.14(1.07)$ \\
Pressure & $2.94(.84)$ & $2.34(.98)$ \\
School activities & $2.71(.76)$ & $2.73(.93)$ \\
Personality development & $2.60(.84)$ & $2.73(.79)$ \\
Control & $2.55(1.06)$ & $2.13(1.05)$ \\
\hline
\end{tabular}

Table 7.

Mean $(M)$, standard deviations $(S D)$ in parental involvement scale subscales between students of low and high academic self-esteem.

\begin{tabular}{ccc}
\hline & $\begin{array}{c}\text { Low academic } \\
\text { self-esteem }\end{array}$ & $\begin{array}{c}\text { High academic } \\
\text { self-esteem }\end{array}$ \\
\cline { 2 - 3 } & $M(S D)$ & $M(S D)$ \\
\hline Homework & $2.05(1.11)$ & $2.24(1.04)$ \\
Pressure & $2.80(.92)$ & $2.45(.96)$ \\
School activities & $2.42(.88)$ & $2.92(.82)$ \\
Personality development & $2.56(.84)$ & $2.75(.77)$ \\
Control & $2.42(1.06)$ & $2.23(1.06)$ \\
\hline
\end{tabular}

Parental Involvement Scale showed the existence of statistically significant correlations. Specifically, parents who get involved to a significant extent with the homework of their child, put at the same time a continuous control over the educational process of their child, but also to some extent this control takes the form of pressure from the parent to their child - student. At the same time, it appears that parents who get involved at home preparing the lessons for their children, participate alongside in school activities more frequently, but also believe that the systematic involvement with their children's learning contributes to the development of the personality of their child. According to many research results (Fan, 2001; Kim, 2002), the effects of parental involvement are long-termed and positively related to childrens' good adjustment indices. Also, according to the results of the correlations of the Parental Involvement Scale factors it seems that parents "associate" or "confuse" the control towards their children with the pressure. The fact should become understandable in the behavior of the parents, because their interest in their children's progress may often evolve into a form of pressure, which the parents do not want, and which may have a negative effect on the progress and the overall development of the child - student. The results are consistent with earlier research (Georgiou, 2000b) indicating that Cyprus parents who put pressure on their children made them question their ability to succeed in school. Finally, commenting on the intercorrelations between the dimensions of the Parental Involvement Scale parents who are engaged in frequent and intense control to their children about their progress, believe at the same time that this contributes to the development of their child's personality.

Thereafter the correlations between the perceived classroom climate, as it was assessed by the selected factors of the Classroom Life Measure, with the factors of the Parental Involvement and Causal Performance Scales were examined. The results of the correlations showed that the pressure on the part of parents contributed to students seeking a higher degree of extrinsic motivation, and also the social support from the school environment by students, possibly in an attempt to compensate for the negative climate experienced from the study and preparation of lessons at school. Also, the negative correlation between pressure and school self-esteem of the students reveals that the more intense the pressure of parents is towards their children to study, the lower the self-esteem the students have about their ability to respond successfully to the requirements of the school, or in other words it reduces the sense of personal competence.

On the other hand, it seems that the student's participation in school activities helps to increase school self-esteem, as a result of the stronger and closer interaction with the other students of the school. As Babalis (2005) indicates the experience that a child gains at school and at home and the interaction with parents and teachers has a direct consequence in its self-concept and general behaviour. Finally it seems that the more developed the personality of the child is, according to the views of the parents, the lower is the effort to find extrinsic motivation and social support on the part of the student. This result is particularly important, and shows the crucial role of parents in personality development of their children, a factor which may contribute to a greater sense of autonomy and personal growth of the child, who will not have the necessity of environmental incentives to achieve the objectives they have set in the educational process. 
The examination of the correlations between the dimensions of Parental Involvement Scale with the factors of State-Trait Anxiety Scale and the positive, negative and general self-esteem showed the existence of statistically significant correlations. Specifically, the results showed that the pressure from their parents to the study the lessons contributed to the increase of the state-anxiety felt by children, but simultaneously to the increase of the negative self-esteem and the restriction of the student's general self-esteem, a fact which shows that the child's feeling of pressure from their parents to prepare and study the lessons contributes to the emergence of negative emotions, but also to the creation of a negative self-esteem on the child's ability to successfully meet the demands of the school.

The same effect, although to a lesser extent, has the feeling of parent's control to their child, which seems to reduce the feeling of general esteem the student has towards them and their general abilities. The Causal Performance Scale with the State-Trait Anxiety Scale and the Self-Esteem Scale did not show significant correlations, except for the fact that the high intelligence of the child was combined with lower negative self-esteem on his part.

The same effect, although to a lesser extent, has the feeling of parent's control to their child, which seems to reduce the feeling of general esteem the student has towards them and their general abilities. The Causal Performance Scale with the State-Trait Anxiety Scale and the Self-Esteem Scale did not show significant correlations, except for the fact that the high intelligence of the child was combined with lower negative self-esteem. The possibility of positive correlation between parental involvement and school success, positive self-esteem, personal development, high expectations and decreased stateanxiety is expected to improve the effectiveness and efficiency of the Greek Educational System and will conduce to its qualitative upgrading.

This research will also contribute to the understanding and interpretation of the problems and dysfunctions that the Greek Education faces in relation to childrens' learning and interpersonal relationships, that will help to their successfully coping and enhancement of the teachers' and parents' work.

The results of the present research indicate that the organization of common meetings and seminars, programs of inclusive education, where both teachers and parents will be able to attend at the same time, is a major step towards a meaningful contact and exchange of views between them. Moreover, the willingness that the parents show to get systematically involved in their childrens' learning and development, could lead to the groundbreaking proposal of an individual "Parents' Curriculum", which will direct and facilitate parents' work at home. Thus, parental involvement and communication between parents and teachers will upgrade the cognitive, social and emotional environment of the children in Greek school.

\section{REFERENCES}

Albright, M. I., \& Weissberg, R. P. (2010). School-family partnerships to promote social and emotional learning. In S. L. Christenson, \& A. L. Reschly (Eds.), Handbook of school-family partnerships for promoting student competence(pp. 246-265). New York: Routledge.

Babalis, Th. (2005). The socialization of child in the classroom. Helping with their school adjustment (in Greek language). Athens: El- linika Grammata.

Babalis Th., \& Katsaouni K. (2011). Family-school relations. Parents' role. Matters of Educational Planning, 4, 148-166.

Berger, E., (2004). Parents as partners in education. Families and schools working together (6th ed.). Upper Saddle River, NJ: Pearson Merrill Prentice Hall.

Bronfenbrenner, U. (1979). The ecology of human development: Experiments by nature and design. Cambridge, MA: Harvard University Press.

Christenson, S., \& Sheridan, S. (2001). Schools and families-Creating essential connections for learning. New York: The Guilford Press.

Epstein, J. (1995). School, family, community partnerships: Caring for the children we share. Phi Delta Kappan, 92, 701-712.

Epstein, J. (2001). School, family, and community partnerships: Preparing educators and improving schools. Boulder, CO: Westview Press.

Epstein, J., Coates, L. et al. (1997). School, family and community partnerships. San Francisco, CA: Corwin Press.

Epstein, J., Sanders, M. et al. (2002). School, family, and community partnerships-Your handbook for action (2nd ed.). Thousand Oaks, CA: Corwin Press, INC.

Fan, X. (2001). Parental involvement and student's academic achievement: A growth modeling analysis. Journal of Educational Research, 80, 330-337.

Georgiou, S. (2000a). School-family relationship and child's development (in Greek language). Athens: Ellinika Grammata.

Georgiou, S. (2000b). The causal effect of the performance from parents, parental involvement and child's performance (in Greek language). Psychology, 7, 191-206

Hoover-Dempsey, K., \& Sandler, H. (1997). Why do parents become involved in their children's education? Review of Educational Research, 67, 3-42.

Hoover-Dempsey, K., Walker, J. et al. (2005). Why do parents become involved? Research findings and implications. Elementary School Journal, 106, 105-130. doi:10.1086/499194

Johnson, D. W., \& Johnson, R. (1983). Social interdependence and perceived academic and personal support in the classroom. Journal of Social Psychology, 120, 77-82. doi: $10.1080 / 00224545.1983 .9712012$

Johnson, D. W., Johnson, R. T., Buckman, L. A., \& Richards, P. S. (1985). The effect of prolonged implementation of cooperative learning on social support within the classroom. Journal of Psychology, 119, 405-411.

Kim, E. (2002). The relationship between parental involvement and children's educational achievement in the Korean immigrant family. Journal of Comparative Family Studies, 33, 529-543.

Milonakou-Keke, H. (2006). Modern theoritical approaches to communication among school, family and community (in Greek language). Athens: Atrapos.

Patrikakou, E., Weissber, R. et al. (2005). School, family partnerships for children's success. The series on social emotional learning. New York: Teachers College Press.

Rosenberg, M. (1965). Society and the adolescent self-image. Princeton, NJ: Princeton University Press.

Ryan, B., \& Adams, G. (1995). The family-school relationships model. In B. Ryan, G. Adams et al. (Eds.), The family school connection (pp. 3-28). Thousand Oaks, CA: Sage Publications.

Spielberger, C. D., Gorsuch, R. L., \& Lushene, R. E. (1970). Manual for the state-trait anxiety inventory. Palo Alto, CA: Consulting Psychologists Press.

Spielberger, C. D., Edwards, C. D., Lushene, R. E., Montuori, J., \& Platzek, D. (1973). The state-trait anxiety inventory for children (preliminary manual). Palo Alto, CA: Consulting Psychologists Press. 